\title{
Effects of Long-Wave UV Light on Monilinia Growth and Identification of Species
}

\author{
A. De Cal and P. Melgarejo, Department of Plant Protection, CIT-INIA, Carretera de La Coruña km 7, 28040 Ma- \\ drid, Spain
}

\begin{abstract}
De Cal, A., and Melgarejo, P. 1999. Effects of long-wave UV light on Monilinia growth and identification of species. Plant Dis. 83:62-65.

The effect of long-wave UV/dark period on mycelial growth of 46 isolates of Monilinia sp. collected in Spain and 16 isolates collected from other parts of the world was investigated. Typical isolates of M. laxa, M. fructigena, and M. fructicola were grown in the dark and identified by morphological characteristics. Long-wave UV/dark conditions reduced the growth rates of M. laxa, M. fructigena, and M. fructicola on potato dextrose agar. All isolates of M. fructigena grew more slowly than those of $M$. fructicola. Typical and atypical isolates of $M$. fructigena and $M$. fructicola were placed in their respective species based on long-wave UV/dark growth rate data. M. laxa isolates were readily distinguished by the short distance from their conidium to the first germ tube branch. The involvement of different photoreceptors in photoresponses by $M$. fructicola and $M$. fructigena is discussed. Differences in mycelial growth under long-wave UV may be a useful tool to identify Monilinia spp.
\end{abstract}

Additional keywords: brown rot of fruit, classification, quarantine organism, taxonomy, wavelength

Brown rot of stone and pome fruit is caused by species of the genus Monilinia, $M$. laxa, M. fructigena, and M. fructicola (2). These fungi infect aerial parts of host plants inducing blight of blossoms and leaves, cankers on woody tissues, and rot of fruits.

The brown rot fungi cause economically important losses in most temperate regions of the world. M. laxa and M. fructigena were initially European species. However, the distribution area of M. laxa now covers most regions where stone and pome fruits are cultivated. $M$. fructigena has been found outside Europe in only a few cases. $M$. fructicola is restricted to Australia, South Africa, and North and South America, and is a European quarantine listed organism (7).

Identification of Monilinia spp. is based on cultural and morphological characters (2). M. fructicola is distinguished from $M$. laxa in having entire colony margins, by color of conidia, absence of hyphal anastomoses between germinating conidia, and longer conidial germ tube extension before branching $(17,18,21)$. M. fructicola produces more abundant conidia, stromata, and spermatia, and has slightly smaller conidia and more narrow hyphal diameter than $M$. fructigena $(17,19)$. M. fructigena has entire colony margins, different conidium color, and longer conidium germ

Corresponding author: P. Melgarejo

E-mail: melgar@inia.es

Accepted for publication 5 October 1998.

Publication no. D-1998-1117-01R

(C) 1999 The American Phytopathological Society tubes than $M$. laxa $(18,19)$. These characteristics assist in the identification of typical cultures of Monilinia spp., but problems arise with atypical cultures. Many differences have been observed among isolates of the same species $(1,2,11,25)$. This variability is especially important when quarantine measures apply to one species but not the other. More reliable and stable characteristics are needed to clearly distinguish one species from another.

Growth, stromatal formation, and sporulation of the three species are affected by illumination (11). The effect of alternate periods of light/dark on growth and sporulation of the three species has been previously studied, especially using daylight $(6,10,11,14,26)$ and different wavelengths from 440 to $760 \mu \mathrm{m}$, but not the ultraviolet range $(12,14)$. However, these studies were not carried out for species identification.

The aim of this work was to determine the influence of long-wave UV light on mycelial growth of Monilinia spp. and its usefulness in differentiating Monilinia species.

\section{MATERIALS AND METHODS}

Isolates. Forty-six isolates of Monilinia spp. were collected from several hosts in different orchards in Spain (Spanish Collection) (Table 1). Mass isolation of the fungus was made in potato dextrose agar (PDA) amended with $0.5 \mathrm{~g}$ of streptomycin sulfate per liter. Sixteen isolates of presumed Monilinia spp. from different parts of the world were also used (World Collection) (Table 2). All isolates were grown in 9-cm-diameter plastic petri dishes containing $12.5 \mathrm{ml}$ of PDA (Oxoid Ltd., Basingstoke, Hampshire, Eng.) at $22^{\circ} \mathrm{C}$ in the dark for conidial and mycelial production. All isolates were stored on PDA slants at $4^{\circ} \mathrm{C}$ in the dark.

Identification of isolates. After 10 days incubation on PDA, the following characteristics were recorded for each isolate: presence or absence of conidia, concentric rings of sporulation, lobed colonies, black rings associated with lobes, and color of the sporogenous tissue. To produce conidia for germination studies, isolates were grown on PDA or PDA amended with $1 \%$ acetone for 10 days in the dark at $22^{\circ} \mathrm{C}$, as recommended by Pascual et al. (20). Colonies that did not produce any sporulation were maintained at 5 to $10^{\circ} \mathrm{C}$ for 60 days, as recommended by Masri (16) and Tamm and Flückiger (23). Conidia were removed from the surface of the colony with a sterile scalpel, suspended in sterile distilled water, and sonicated for $1 \mathrm{~min}$. A $100-\mu \mathrm{l}$ droplet of the conidia suspension $\left(10^{3}\right.$ conidia/ml) was spread on petri dishes containing distilled water agar (DWA, 2\% agar, Oxoid). These dishes were incubated for $24 \mathrm{~h}$ at $22^{\circ} \mathrm{C}$ in the dark. Three replicates were made per isolate. The distance in micrometers from the conidium to the first germ tube branch was measured for 25 conidia, using Zeiss optical microscopy $(\times 100)$ equipped with an ocular micrometer. A conidia was considered germinated when the germ tube was longer than the length of the conidia. This procedure was performed twice.

Effect of long-wave UV light on mycelial growth. PDA dishes were centrally inoculated with 4-mm-diameter plugs from the margin of 4-day-old PDA cultures. Six dishes were used for each isolate. Three dishes were wrapped with aluminum foil and placed in unlighted incubators at $22^{\circ} \mathrm{C}$. The other three plates were incubated at 16-h long-wave UV/8-h dark photoperiod under a Phillips TLD 18W/08 light (black light 320 to $380 \mathrm{~nm}$ ). These plates were placed approximately $15 \mathrm{~cm}$ from the light source. Temperatures were maintained at $18^{\circ} \mathrm{C}$ in the dark and $22^{\circ} \mathrm{C}$ in the light. Colony growth in each replicate plate was recorded 3 and 5 days after inoculation by measuring two perpendicular diameters. Growth rates (difference between diameters at days 5 and 3) were calculated for each replicate in both incubation conditions. The experiment was conducted once for the Spanish collection and twice for the world collection. The effect of long-wave UV light was assessed by calculating the percent inhibition of colony growth rate (PIGR) for each isolate using the formula 
PIGR $=\left[1-\left(G_{L} / G_{D}\right)\right] \times 100$, where $\mathrm{GR}_{\mathrm{L}}$ is the growth rate in 16-h long-wave $\mathrm{UV} / 8$-h dark, and $\mathrm{GR}_{\mathrm{D}}$ is the growth rate in the dark conditions, respectively.

Data analysis. Distance from conidia to first germ tube branch, colony growth rate, and PIGR were analyzed by protected analysis of variance, and means were compared by a least significant difference (LSD) test at $P=0.05$. Distance from conidia to first germ tube branch and growth rate were $\mathrm{x} / \Sigma \mathrm{x}$ transformed before analysis to improve homogeneity of variances. PIGR was arcsine transformed.

\section{RESULTS}

Identification of isolates. Typical isolates of M. laxa, M. fructigena, and $M$. fructicola were identified on PDA by the cultural and morphological characteristics described previously. It was not possible to identify atypical isolates (W-1, W-9, and W12) by the cultural and morphological characteristics. Isolate W-12 did not sporulate.

The distance from the conidium to the first germ tube branch in DWA clearly separated isolates into two groups (Tables 1 and 2). In the first group, germ tubes branched soon after conidia germination. The distance from the conidium to the first germ tube branch was less than $60 \mu \mathrm{m}$. Isolates within this group are considered to be $M$. laxa $(2,8,13,18,27)$. There were 36 Spanish isolates (ES-1 to ES-40, ES-50, and ES-52) and five world isolates (W-3, W-6, W-8, W-10, and $\mathrm{W}-15$ ) in this group. Only $26 \mathrm{M}$. laxa isolates of the Spanish collection and four of the world collection produced colonies of lobed margins (Tables 1 and 2), one of the characteristics defining this species. Sporogenous tissue of the Spanish M. laxa isolates were gray or gray/buff. Sporogenous tissue of the isolates from the world collection identified as M. laxa was gray or gray-buff, except for isolate W-15, which was buff.

The isolates in the second group had germ tubes that grew as single, almost straight hyphae, at least $220 \mu \mathrm{m}$ long before branching, sometimes reaching $960 \mu \mathrm{m}$ when this group was further characterized using the morphological characteristics described above. Differences between isolates were evident, particularly with regard to color of the sporogenous tissue and the characteristics of the margins of colonies (Tables 1 and 2). Among these isolates, ES41 to Es-49, ES-51, W-13, W-14, W-17, and

Table 1. Characteristics of Monilinia isolates from Spanish collection

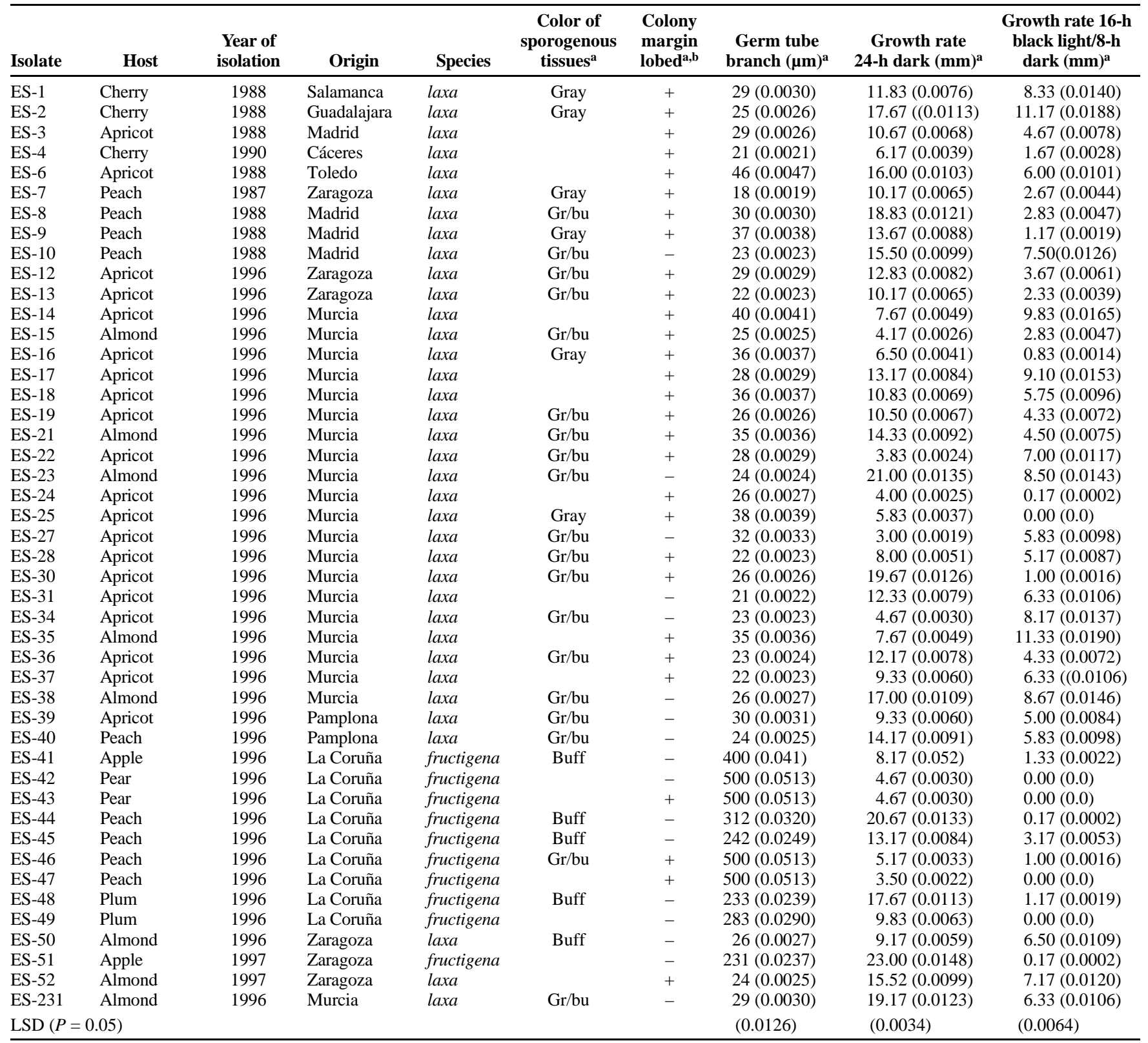

${ }^{\text {a }}$ Data of color of the sporogenous tissue, presence of lobed colonies, germ tube branch, and growth rate are the means of three replicates. gr $=$ gray, bu $=$ buff. Data in brackets were $(\mathrm{x} / \Sigma \mathrm{x})$ normalized before analysis.

b None of the isolates exhibited concentric rings of sporulation. 
Table 2. Characteristics of Monilinia isolates from the world collection growing in the darkness

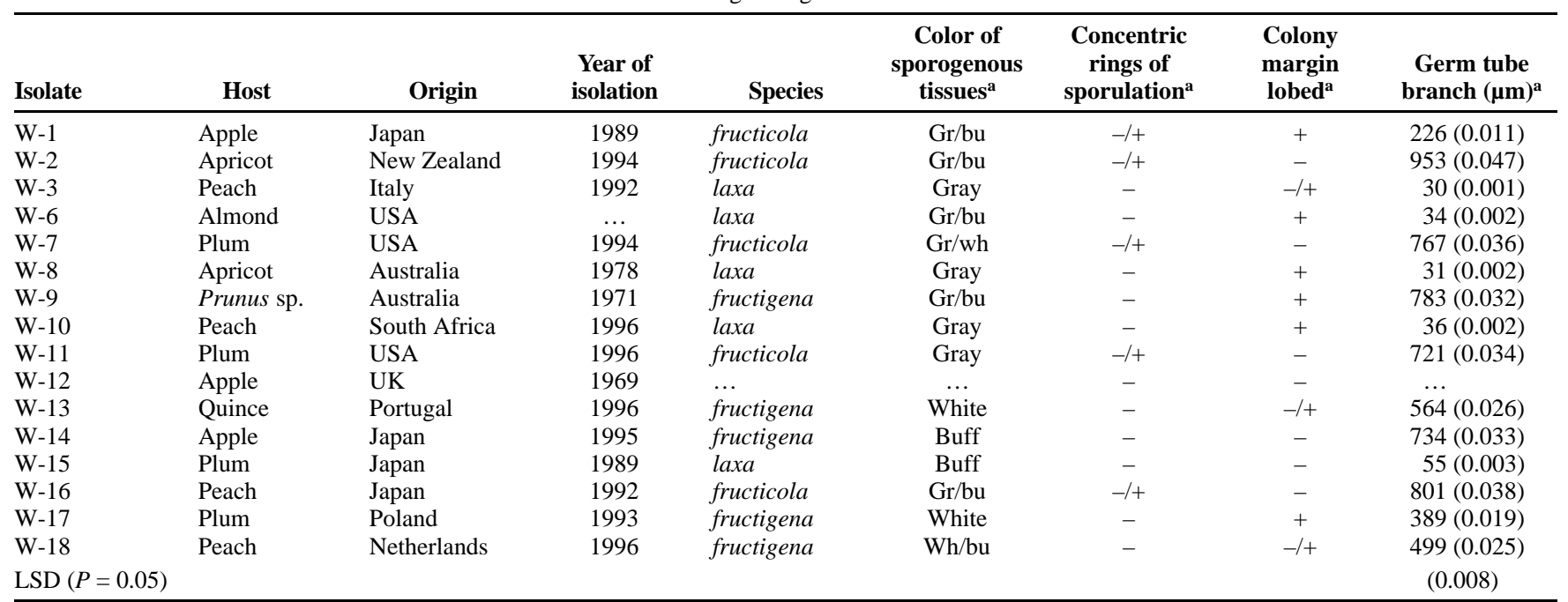

a Data of concentric rings of sporulation, color of the sporogenous tissue, presence of lobed colonies, and germ tube branch are the means of three replicates. $\mathrm{gr}=$ gray, $\mathrm{bu}=$ buff, $\mathrm{wh}=$ white. Data in brackets were $(\mathrm{x} / \Sigma \mathrm{x})$ normalized before analysis.

Table 3. Growth rate $(\mathrm{mm})$ of Monilinia isolates from the world collection grown on potato dextrose agar (PDA) in 16-h black light/8-h dark and 24-h dark in two experiments

\begin{tabular}{lcrrrr}
\hline & \multicolumn{2}{c}{ 16-h black light/8-h dark } & & \multicolumn{2}{c}{ 24-h dark } \\
\cline { 2 - 3 } \cline { 5 - 6 } Isolate & Experiment 1 & Experiment 2 & & Experiment 1 & Experiment 2 \\
\hline W-1 & $11.67(0.0158)^{\mathrm{a}}$ & $18.50(0.0251)$ & & $13.83(0.0087)$ & $25.00(0.0158)$ \\
W-2 & $16.30(0.0221)$ & $20.00(0.0272)$ & & $22.33(0.0141)$ & $25.67(0.0162)$ \\
W-3 & $5.00(0.0068)$ & $10.00(0.0136)$ & & $17.33(0.0109)$ & $15.33(0.0097)$ \\
W-6 & $8.50(0.0115)$ & $11.33(0.0154)$ & & $12.33(0.0078)$ & $11.33(0.0071)$ \\
W-7 & $13.17(0.0179)$ & $15.50(0.0211)$ & & $25.50(0.0161)$ & $24.83(0.0157)$ \\
W-8 & $8.50(0.0115)$ & $8.17(0.0111)$ & & $11.67(0.0073)$ & $13.50(0.0085)$ \\
W-9 & $2.83(0.0038)$ & $3.33(0.0045)$ & & $8.50(0.0053)$ & $11.00(0.0069)$ \\
W-10 & $8.17(0.0111)$ & $7.50(0.0102)$ & & $6.17(0.0039)$ & $9.50(0.0060)$ \\
W-11 & $9.33(0.0127)$ & $14.67(0.0199)$ & & $23.67(0.0149)$ & $20.83(0.0132)$ \\
W-13 & $0.17(0.0002)$ & $1.50(0.0020)$ & & $3.00(0.0019)$ & $4.50(0.0028)$ \\
W-14 & $3.33(0.0045)$ & $7.67(0.0104)$ & & $11.17(0.0070)$ & $22.17(0.0140)$ \\
W-15 & $1.67(0.0022)$ & $5.67(0.0077)$ & & $10.17(0.0064)$ & $5.67(0.0035)$ \\
W-16 & $13.00(0.0176)$ & $17.33(0.0235)$ & & $27.33(0.0173)$ & $31.00(0.0196)$ \\
W-17 & $0.0(0.0)$ & $1.5(0.0020)$ & & $5.67(0.0035)$ & $6.17(0.0039)$ \\
W-18 & $0.17(0.0002)$ & $0.5(0.0006)$ & & $3.33(0.0021)$ & $2.83(0.0017)$ \\
LSD $(P=0.05)$ & $(0.0061)$ & $(0.0062)$ & & $(0.0020)$ & $(0.0026)$ \\
\hline
\end{tabular}

a Data are the means of three replicates. Colony growth was recorded 3 and 5 days after inoculation by measuring two perpendicular diameters in each replicate. Growth rate (difference between diameters at days 3 and 5) was calculated for each replicate under both sets of incubation conditions. Data in brackets were $(\mathrm{x} / \Sigma \mathrm{x})$ normalized before analysis.

W-18 were identified as $M$. fructigena, while isolates $\mathrm{W}-2, \mathrm{~W}-7, \mathrm{~W}-11$, and $\mathrm{W}-16$ were identified as M. fructicola.

Effect of long-wave UV light on mycelial growth. Growth rates of all isolates were significantly affected by long-wave UV (Tables 1 and 3). Growth in the dark was faster $(P=0.05)$ than growth under long-wave UV/darkness. The mean growth rates for M. laxa were $11.3 \pm 0.82$ and 5.36 \pm 0.5 (Spanish collection), and $11.53 \pm 1.8$ and $6.37 \pm 1.34$ (world collection) in the dark or long-wave UV/dark, respectively. For $M$. fructigena, growth rates were 11.05 \pm 2.27 and $0.7 \pm 0.32$ (Spanish collection) and $6.33 \pm 1.55$ and $1.3 \pm 0.73$ (world collection) in the dark or long-wave UV/dark, respectively. For $M$. fructicola, growth rates were $22.53 \pm 2.33$ and $11.83 \pm 1.86$ (world collection) in the dark or long-wave UV/dark, respectively. Growth rates of $M$. fructicola were faster than those of $M$. fructigena or M. laxa under both test conditions. However, there were some Spanish isolates of M. fructigena (ES-44 and ES-51) and $M$. laxa (ES-23) with similar growth rates to those of $M$. fructicola, when grown in the dark. Under alternating long-wave UV/ darkness conditions, all the isolates of $M$. fructigena grew more slowly (up to $8 \mathrm{~mm}$ ) than those of M. fructicola.

The PIGR of $M$. fructigena by the longwave UV/dark cycle was the highest (93 and $80 \%$ in Spanish and world isolates, respectively), followed by that of M. laxa (63 and $31 \%$ in Spanish and world isolates, respectively) and M. fructicola (38\% in world isolates) (Fig. 1).

\section{DISCUSSION}

$M$. laxa isolates can be easily distinguished from $M$. fructigena and $M$. fructi- cola in DWA by the characteristic shortdistance germ tube elongation from the conidium to the first germ tube branch (shorter than $60 \mu \mathrm{m}$ ). M. fructigena and $M$. fructicola both produced germ tubes that grew for at least $220 \mu \mathrm{m}$ before branching. These two species were clearly differentiated from each other under long-wave UV/dark conditions. Maximum growth rate of $M$. fructigena was $8 \mathrm{~mm}$, while maximum growth rate of $M$. fructicola was $20 \mathrm{~mm}$. This difference may indicate that different photoreceptors may be present in the two species $(15,22,24)$. Isolate $\mathrm{W}-1$, which was similar in appearance to $M$. fructigena when grown on PDA in the dark, was identified as M. fructicola based on growth in long-wave UV/dark cycle. Isolate W-9, which was similar in appearance to M. fructicola when grown on PDA in the dark, was identified as M. fructigena.

Long-wave UV/dark conditions reduced the growth rates $(P=0.05)$ of the three Monilinia species on PDA. The small fluctuations in temperature associated with the light cycle did not affect growth rate. Temperature has been shown to affect growth of Monilinia spp., but for wider fluctuations than the ones registered in our experiment $(11,23)$. Fungal responses to light frequently include changes in growth, reproduction, or both (5). Wavelengths producing these responses are usually in the ultraviolet and blue regions of the spectrum (4). As reported by Hall (10) and Janitor (12), M. fructigena showed faster growth and formation of fruiting organs in light of wavelength between 440 and 490 $\mu \mathrm{m}$ or under alternating light/dark conditions. Alternation of diurnal illumination and darkness (16-h light/8-h dark) did not affect growth of $M$. fructicola and M. laxa (26). Harada (11) also observed no inhibitory effect of daylight fluorescent light on mycelial growth of $M$. laxa, $M$. fructigena, and M. fructicola. 


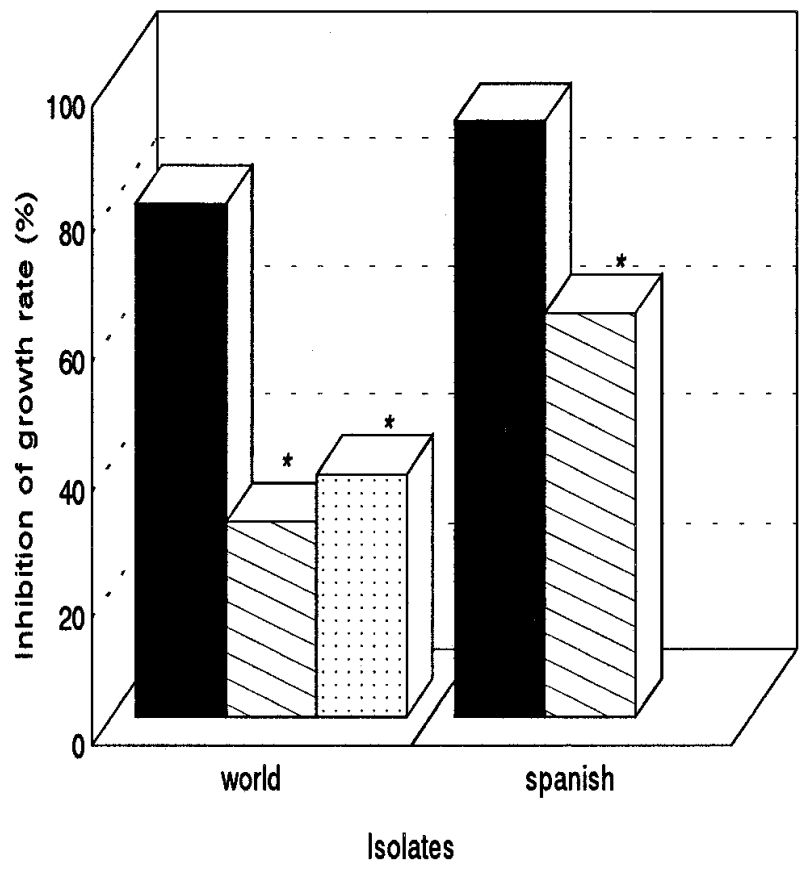

Fig. 1. Percent inhibition of growth rate (PIGR) of Monilinia fructigena (solid), M. laxa (diagonal lines), and M. fructicola (dots) in Spanish and world isolates by exposure to long-wave UV light. Columns with an asterisk for each collection are significantly different $(P=0.05)$. PIGR for each isolate was calculated by the formula PIGR $=\left[1-\left(\mathrm{GR}_{\mathrm{L}} / \mathrm{GR}_{\mathrm{D}}\right)\right] \times 100$, where $\mathrm{GR}_{\mathrm{L}}$ and $\mathrm{GR}_{\mathrm{D}}$ are the growth rates in 16-h long-wave UV/8-h dark conditions, respectively. Values are the means of isolates of each species in each collection.

The type of germ tube growth has been previously used to separate the brown rot species (2). Wormald (27) observed that germ tubes of $M$. fructigena grow from 400 to $1,200 \mu \mathrm{m}$ before branching, while germ tubes of M. laxa (M. cinerea) become geniculate and produce early branches at a short distance from its point of origin. $M$ fructicola resembles $M$. fructigena in the unbranched germ tube at least $200 \mu \mathrm{m}$ long but sometimes up to $750 \mu \mathrm{m}$ (2). The differences in the growth patterns of germ tubes of M. fructicola and M. laxa have been confirmed by Ezekiel (8) and Jenkins (13), who found that germ tubes of Sclerotinia laxa commonly branched before they were $50 \mu \mathrm{m}$ long; whereas $S$. fructicola remained unbranched up to $700 \mu \mathrm{m}$. Mordue (18) reported that $M$. laxa germ tubes branched before those of $M$. fructigena and M. fructicola. However, Calavan and Keitt (3) indicated that differences in germ tube branching can be affected by nutritional conditions. Our results were obtained using a culture medium with very few nutrients, and they clearly distinguished $M$. laxa from the other two species.

The study of mycelial growth under long-wave UV may be a useful tool to identify Monilinia spp. A combination of both observations (distance from the conidium to the first germ tube branch and growth rate under long-wave UV/dark cycle) produced a satisfactory method for differentiating species of Monilinia, although at least 9 days are needed to obtain results. Molecular and enzymatic techniques may be a more rapid method for the identification of the species. A species-specific primer for $M$. fructicola is already available (9).

\section{ACKNOWLEDGMENTS}

We thank Van Kesteren (Plant Protection Service, Wageningen, The Netherlands), A. Lucas, M. Cambra, and J. Muro for kindly providing isolates of Monilinia. We thank S. Pascual for critically reading the manuscript and C. Simón for technical assistance. This work has been carried out with financial support from the Commission of the European Communities, Agriculture and Fisheries (FAIR) specific RTD program, Fair 1-0725, "Development of diagnostic methods and a rapid field kit for monitoring Monilinia rot of stone and pome fruit, especially $M$. fructicola." It does not necessarily reflect its views and in no way anticipates the Commission's future policy in this area.

\section{LITERATURE CITED}

1. Batra, L. R. 1979. First authenticated North American record of Monilinia fructigena, with notes on related species. Mycotaxon 8:476-484

2. Byrde, R. J., and Willetts, H. J. 1977. The Brown Rot Fungi of Fruit. Their Biology and Control. Pergamon Press, Oxford.

3. Calavan, E. C., and Keitt, G. W. 1948. Blossom and spur blight (Sclerotinia laxa) of sour cherry. Phytopathology 38:857-882.

4. Calpouzos, L., and Chang, H.-S. 1971. Fungus conidia germination inhibited by blue and far red radiation. Plant Physiol. 47:729-730.

5. Carlile, M. J. 1965. The photobiology of fungi. Annu. Rev. Plant Physiol. 16:175-202.

6. Dickson, H. 1939. The effect on the growth of Sclerotinia fructigena of alternating periods of light and darkness of equal length. Ann. Bot. 3:131-136.

7. EPPO. 1992. Quarantine Pests for Europe. I. M. Smith, D. G. McNamara, P. R. Scott, and K. M. Harris, eds. CAB International, Oxford.

8. Ezekiel, W. N. 1924. Fruit rotting Sclerotin- ias. II. The American brown rot fungi. Bull. Md. Agric. Exp. Stn. 271:87-142.

9. Fulton, C., and Brown, A. E. 1997. Use of SSU rDNA group-I intron to distinguish Monilinia fructicola from $M$. laxa and $M$. fructigena. FEMS Microbiol. Lett. 157:307-312.

10. Hall, M. 1933. An analysis of the factors controlling the growth form of certain fungi, with especial reference to Sclerotinia (Monilia) fructigena. Ann. Bot. Lond. 47:543-578.

11. Harada, Y. 1977. Studies on the Japanese species of Monilinia (Sclerotiniaceae). Bull. Fac. Agric. Hirosaki Univ. 27:30-109.

12. Janitor, A. 1970. Influence of artificial radiation on the vegetative growth and the formation of the fruiting organs in Monilia fructigena (Pers. ex Pers.) Steud. Ceská Mykologie 24:198-206.

13. Jenkins, P. T. 1965. Sclerotinia laxa Aderh. \& Ruhl.: A cause of brown rot of stone fruits not previously recorded in Australia. Aust. J. Agric. Res. 16:141-144.

14. Jerebzoff, S., and Jacques, R. 1972. Equal quantal spectra for the effect of light on the growth of conidiophores and for the induction of a circadian rhythm of zonation in Sclerotinia fructicola (Wint.) Rehm. Plant Physiol. 50:187-190.

15. Leach, C. M., and Trione, E. J. 1965. An action spectrum for light induced sporulation in fungus Ascochyta pisi. Plant Physiol. 40:808-812.

16. Masri, S. S. 1967. An improved technique for studying spore germination of Sclerotinia laxa. Phytopathology 57:997.

17. Mordue, J. E. M. 1979. Sclerotinia fructicola. Descriptions of pathogenic fungi and bacteria. $\mathrm{N}^{\circ}$ 616. Commonw. Mycol. Inst./Assoc. Appl. Biol., Kew, Surrey, Eng.

18. Mordue, J. E. M. 1979. Sclerotinia laxa Descriptions of pathogenic fungi and bacteria $\mathrm{N}^{\circ}$ 619. Commonw. Mycol. Inst./Assoc. Appl. Biol., Kew, Surrey, Eng.

19. Mordue, J. E. M. 1979. Sclerotinia fructigena Descriptions of pathogenic fungi and bacteria $\mathrm{N}^{\circ}$ 617. Commonw. Mycol. Inst./Assoc. Appl. Biol., Kew, Surrey, Eng.

20. Pascual, S., De Cal, A., and Melgarejo, P. 1990. Induction of conidia production by Monilinia laxa on agar media by acetone. Phytopathology 80:494-496.

21. Penrose, L. J., Tarran, J., and Wong, A. L. 1976. First record of Sclerotinia laxa Aderh \& Ruhl. in New South Wales: Differentiation from S. fructicola (Wint.) Rehm. by cultural characteristics and electrophoresis. Aust. J. Agric. Res. 27:547-556.

22. Perkins, J. H., and Gordon, S. A. 1969. Morphogenesis in Schizophyllum commune. II. Effects of monochromatic light. Plant Physiol. 44:1712-1716.

23. Tamm, L., and Flückiger, W. 1993. Influence of temperature and moisture on growth, spore production, and conidial germination of Monilinia laxa. Phytopathology 83:1321-1326.

24. Van den Ende, G., and Cornelis, J. J. 1970 The induction of sporulation in Sclerotinia fructicola and some other fungi and the production of " $\mathrm{P}_{310}$ ". Neth. J. Plant Pathol. 76:183-191.

25. Wilcox, W. F. 1989. Influence of environment and inoculum density on the incidence of brown rot blossom blight of sour cherry. Phytopathology 79:530-534.

26. Willetts, H. J. 1969. Cultural characteristics of the brown rot fungi (Sclerotinia spp.). Mycologia 61:332-339.

27. Wormald, H. 1920. The "brown rot" diseases of fruit trees, with special reference to two biologic forms of Monilia cinerea, Bon. II. Ann. Bot. 34:143-171. 